\title{
Farklı Toprak Özelliklerinin Taban Çayırların Floristik Kompozisyonu Üzerine Etkisi
}

\author{
*Süleyman TEMEL ${ }^{1}$ Uğur ŞiMŞEK ${ }^{2}$ Erhan ERDEL ${ }^{2}$ \\ Faruk TOHUMCU ${ }^{2} \quad$ Fatih GÖKMEN ${ }^{2}$
}

${ }^{1}$ Iğdır Üniversitesi, Ziraat Fakültesi, Tarla Bitkileri Bölümü, Iğdır

${ }^{2}$ Iğdır Üniversitesi, Ziraat Fakültesi,Toprak Bilimi ve Bitki Besleme Bölümü, Iğdır

*Sorumlu yazar e-posta (Corresponding author e-mail): stemel33@hotmail.com

\section{Öz}

Bir bölgede çayır ve mera alanları ile ilgili uygun ıslah ve yönetim çalışmalarının uygulanabilmesi için, öncelikle mevcut vejetasyonların tür bileşiminin tespit edilmesi gerekmektedir. Iğdır ovasının tuz etkisine maruz kalan taban arazilerinin büyük bir kısmında tarla tarımı yapılamamakta ve otlatılarak ya da biçilerek değerlendirilmektedir. Bu çalışma daha önce bitki örtüsü hakkında hiç çalışma yapılmamış, toprak tuzluluğundan farklı düzeyde etkilenmiş doğal kurak taban çayır kesimlerinin tür bileşimini ve aralarındaki farklılıkları tespit etmek ve sonrasında yapılacak çalışmalara altıı oluşturmak amacıyla yürütülmüştür. Çalışmada 2012 ve 2013 yıllarında dört çayır kesiminde tuzlu (EC = 4.82 dS/m, DSY =\%11.6), alkali (EC = $1.48 \mathrm{dS} / \mathrm{m}, \mathrm{DSY}=\% 39.1)$, tuzlu-alkali $(\mathrm{EC}=4.31 \mathrm{dS} / \mathrm{m}, \mathrm{DSY}=\% 39.7)$ ve tuzluluk problemi olmayan $(\mathrm{EC}=$ $0.4 \mathrm{dS} / \mathrm{m}$, DSY = \%4.3) çayır kesimlerinde hâkim türlerin çiçeklenme dönemi sonunda Quadrat yöntemi (0.5 x $0.5=0.25 \mathrm{~m}^{2}$ ) kullanılarak vejetasyon ölçümleri yapılmıştır. Buna göre tuzluluk problemi olmayan çayır kesiminde 39 , tuzluluk sorunu olan çayır kesiminde 41 , alkalilik sorunu olan çayır kesiminde 38 ve tuzluluk ve alkalilik sorunu olan çayır kesiminde 26 tür tespit edilmiştir. Çalışma sonucunda çayır kesimlerinin tür bileşimlerinin özellikle familya bazında farkılık gösterdiği, normal koşullara göre tuz etkisinde kalmış çayır kesimlerinde baklagil tür sayısının daha az olduğu ve hayvanlar tarafından daha az tercih edilen tür sayının artığı belirlenmiştir.

Anahtar Kelimeler: Çayır vejetasyonu, tuzlu-alkali, tuz stresi, tür bileşimi

\section{Effects of Different Soil Features on Floristic Composition of Ground Meadows}

\begin{abstract}
To conduct appropriate reclamation and management practices on grasslands in a region, it is necessary to first determine species composition of available vegetation. Field agriculture cannot be conducted in a large part of ground lands exposed to salinity in Igdir Plain, and the lands are benefited by grazing or reaping. Study was conducted with the aim of determining species composition of never before studied natural ground meadows affected by salinity at different levels and the differences between them, and providing a base for subsequent studies. Vegetation measurements in meadow zones with no salinity problems $(E C=0.4 \mathrm{dS} / \mathrm{m}$, $\mathrm{DSY}=4.3 \%)$, saline $(\mathrm{EC}=4.82 \mathrm{dS} / \mathrm{m}, \mathrm{DSY}=11.6 \%)$, alkaline $(\mathrm{EC}=1.48 \mathrm{dS} / \mathrm{m}, \mathrm{DSY}=39.1 \%)$, and saline-alkaline $(E C=4.31 \mathrm{dS} / \mathrm{m}, \mathrm{DSY}=39.7 \%)$ in the years of $2012-2013$ were carried out with Quadrat method $(0.5 \times 0.5=0.25$ $\mathrm{m}^{2}$ ) at the end of blossoming period of dominant species. Accordingly, 39 species from the meadow zone with no salinity problem, 41 species from that with salinity problem, 38 species from that with alkaline problem, and 26 from that with saline-alkaline problem were determined. As a result, it was found that species composition of meadow zones differed according to family in particular, that decreased the number of legume species in saline conditions, and that the number of species less preferred by animals increased.
\end{abstract}

Keywords: Meadow vegetation, saline-alkaline, salinity stress, species composition 


\section{Giriş}

$\mathrm{B}^{\mathrm{s}}$ ugün dünyada çiftlik hayvanlarının gereksinim duyduğu yeminin yaklaşık \%70'i çayır-mera alanlarından karşılanmaktadır (Lund 2007). Türkiye'nin yaklaşık \%18'ini kaplayan çayır mera alanları (TÜİK 2013), dünya da olduğu gibi Türkiye'de de hayvanların gereksinim duyduğu kaba yemi en ekonomik yoldan sağlayan kaynakların başında olmasının yanı sıra (Aydın ve Uzun, 2002) biyolojik çeşitlilik yaratması, kültür bitkileri için gen kaynağı durumunda olması, yaban hayvanlarına barınma alanı sağlaması ve toprağı erozyona karşı koruması gibi pek çok önemli görevleri de üstlenmiştir (Açıkgöz 2001). Iğdır ilinde de 358800 ha'lık toplam arazi varlığının 146571 ha'ı çayır mera alanları olup, üretilen kuru ot miktarı 73286 tondur (Temel ve Şahin 2011). Gerekli ve yeterli ıslah çalışmalarının yapılmaması ve yıllardır uygulanan aşırı ve bilinçsiz uygulama teknikleri, mevcut çayır mera alanlarının üretim güçlerini kaybetmesine ve erozyona açık alanlar haline dönüşmesine neden olmuştur (Tükel ve Hatipoğlu 2001). Özellikle son yıllarda ekstrem iklim ve toprak koşullarının yaşandığı çayır ve mera alanlarında amenajman ve ıslah çalışmalarının eksikliği ve çözüm arayışları daha da önem arz etmiştir. İnsanlık ve çevre için önemine rağmen çayır mera alanlarında bozulma sadece ülkemizde değil dünyanın birçok yerinde problemdir. Bu problemler özellikle bizim gibi çayır meraları ortak kullanılan ülkelerde çok daha yoğundur. Çayır meralardaki problemleri düzeltmek çiftçilerin ve karar vericilerin yerinde akılı karar vermelerine bağlıdır. Bunun için ise doğru ve kaliteli bilgiye intiyaç vardır. Çayır meralarda biomas üretimini belirleyen birincil unsur toprak olduğu için, mera yönetiminde toprak özellikleri ve sınıflaması ile ilgili bilgiler öncelikli öneme sahiptir. Mera yönetiminde önemli toprak özellikleri tekstür, strüktür, toprak derinliği, $\mathrm{pH}$, organik madde ve bitki besin elementleri içeriği olarak sıralanabilir. Bu faktörlerin hem birbiriyle ve hem de iklim ve topoğrafya ile olan ilişkisi belli bir bölgede oluşacak vejetasyonun tipini ve üretim potansiyelini belirler (Holecheck et al. 1995).

Bu amaçla dünyada ve ülkemizde marjinal alanların iyileştirilmesine yönelik farklı materyal ve yöntemler kullanılarak yapılmış ve yapılmakta olan çok sayıda çalışma bulunmaktadır (Kushiev et al. 2005; Joachim et al. 2007). Özellikle de bölgenin ekolojik koşullarına adapte olmuş, tabii çayır meralarda kendiliğinden yetişen türlerle başarıya ulaşmanın daha akıllıca olacağı kanaati oluşmuştur. Ancak bu gibi ıslah çalışmalarının etkin bir şekilde yapılabilmesi için de, öncelikle bölgenin flrositik kompozisyonunun çıkarılması ve türler içerisinde; adaptasyon kabiliyeti yüksek, ekstrem dönemlerde dahi yeşilliğini, üretim güçlerini ve kalitesini koruyabilen türlerin tespit edilmesi gerekmektedir.

Bugün Dünya da ve ülkemizde farklı amaçlar doğrultusunda çayır mera alanlarında yürütülmüş pek çok floristik kompozisyon çalışmaları yer almaktadır. Örneğin Koç ve Gökkuş (1996), Palandöken dağları mera vejetasyonlarında yer alan bitkilerin önemli bazı özelliklerini ortaya koymak amacıyla yaptığı çalışmada, araştırma sahasında rastlanılan 152 bitki türünden 21'ini buğdaygillerin, 20'sini baklagiller ve 111'ini diğer familyalara ait bitkilerin oluşturduğu, bu bitkilerden 15'inin iyi, 19'unun orta 102'sinin orta yem değerine sahip olurken 16 türün zehirli bitkiler grubunda yer aldığını bildirmiştir. Yine Çetik (1985), İç Anadolu'nun vejetasyonu incelemiş ve Konya ovası steplerinde çorakçıl (Artemisia santonicum, Salvia cryptantha, Astragalus microcephalus, Trigonella monantha, Atriplex convululata, Alyssum strigasum Juncus maritimus, Atropis distans var. convulata, Aleuropus littoralis, Frankenia hirsuta, Limonium iconia, Obione portulacoides, Salsola inermis) bitkilerin oldukça yaygın olduğunu ortaya koymuştur. Konu ile ilgili Gomez Mercado et al. (2012), tuzlu alanlarda Phragmites australis, Suaeda vera, Sportinia densiflora, Sarcocornia fruticosa, Arthrocnemum macrostrachyum, Astrecicus maritumus, Asparagus horridus, Salsola vermiculata, Typha dominguensis ve Tamarix galica türlerine rastladığını ve tuzluluğa dayanıklı bitkiler olduğunu belirlemişlerdir. Yürütülen başka bir çalışmada Böylelikle yapılan çalışmalar, arzulanan türlerin bozulup-terk edilen çayır mera alanlarının rehabilitasyonu için büyük bir potansiyele sahip olduğu ortaya konulmaya çalışılmıştır.

Uygun ıslah ve yönetim çalışmalarını belirlemek için çayır ve meraların mevcut durumlarının bilinmesi veya ortaya konulması gerekmektedir. Iğdır yöresinde konu ile ilgili çalışmaların sayısı oldukça sınırlıdır. Bu çalışma ile büyük bir kısmı değişik derecede tuzdan etkilenmiş olan Iğdır ovasında gelişmiş taban çayırların floristik kompozisyonunu belirleyerek, 
uygun idare ve ıslah yöntemleri için çözüm önerilerinin geliştirilmesine altyapı hazırlamak hedeflenmiştir. Dolayısı ile yapılan vejetasyon analizi ile taban çayırların geçmişteki kullanım şiddeti, mevcut durumu ortaya konulmuş, aynı zamanda ileride bitki örtüsü ve toprak şartlarında meydan gelecek olumlu veya olumsuz yöndeki değişimin belirlenmesine hizmet edilmiştir.

\section{Materyal ve Yöntem}

Iğdır ovasının tuzlu alkali özelliğe sahip doğu kesiminde yayılış gösteren doğal çayır alanları araştırma materyalini oluşturmuştur. Deneme; kurak iklim özelliği gösteren Iğdır İli, Aralık ilçesine bağlı Saraçlı ve Aşağı Çamurlu köyleri sınırları içerisinde kalan taban çayır arazilerde kurulmuştur. Çalışma aynı iklim bölgesinde yer alan, ancak toprak özellikleri farklı tuzlu (EC= $4.8 \mathrm{dS} / \mathrm{m}, \mathrm{ESP}=\% 11.6)$, alkali $(E C=1.5 \mathrm{dS} / \mathrm{m}$, $\mathrm{ESP}=\% 39.1)$, tuzlu-alkali $(\mathrm{EC}=4.3 \mathrm{dS} / \mathrm{m}, \mathrm{ESP}=$ \%39.7) ve tuz içermeyen $(E C=0.4 \mathrm{dS} / \mathrm{m}$, $\mathrm{ESP}=$ \%4.3) çayır kesimlerinde 2012-2013 yıllarında iki yıl süreyle yürütülmüştür. Deneme materyali olarak seçilen çayır kesimlerin her biri 10 da alana sahip olup, deniz seviyesinden yüksekliği 825 m'dir. Araştırma sahasının uzun yıllar ortalamasına göre ortalama yıllık yağış, nispi nem ve sıcaklık değerleri sırasıyla $264.0 \mathrm{~mm}$, $\% 51.2$ ve $12.5^{\circ} \mathrm{C}$ 'dir. Denemenin yürütüldüğü 2012 ve 2013 yıllarında ise; ortalama yıllık yağış miktarları sırasıyla $237.2 \mathrm{~mm}$ ve $226.9 \mathrm{~mm}$, nispi nem yüzdeleri sırasıyla $\% 53.6$ ve $\% 51.4$, ortalama sıcaklık değerleri sırasıyla $13.5^{\circ} \mathrm{C}$ ve $14.06^{\circ} \mathrm{C}$ olarak ölçülmüştür (Anonim 2014).

Çayır kesimlerinden $(0-30 \mathrm{~cm})$ alınan toprakların bazı fiziksel ve kimyasal özellikleri Çizelge 1'de verilmiştir. Bu sonuçlara göre kumlu-killi tına sahip tuzlu çayır kesimi hariç, diğer çayır kesimleri killi-tınlı toprak bünyesine sahip olmuştur. Toprakların kireç içerikleri incelendiğinde tüm çayır kesimlerinin orta kireçli sınıfta bulunduğu ve fosfor içeriklerinin ise düşük olduğu belirlenmiştir. Tuz içermeyen çayır kesimlerin organik madde içeriğinin orta sınıfta, tuzlu kesimin düşük, alkali ve tuzlu-alkali kesimlerin ise çok düşük sınıfta yer aldığı görülmüştür. Bor içeriği bakımından tuz içermeyen çayır kesimi düşük sınıfta yer alırken, diğer çayır kesimlerinde ise bor, toksik sınırın üzerinde yer aldığı görülmüştür (Anonim 1980, 2002a, 2002b). Araştırmada çayır kesimlerinin arazi etütleri 2012 yılı Mart ayında yapılmış ve
2012 yılı Nisan ayında floristik kompozisyon çalışmalarına başlanılmıştır. Bilindiği üzere tür bileşimi çevre ve rekabet şartlarının etkisi altında mevsimsel olarak değişim gösterebileceğinden, bu çalışmada tür sayısının belirlenmesi hâkim türlerin çiçeklenme döneminin sonunda yapılmıştır. Vejetasyon ölçümleri için öncellikle her bir çayır kesiminde araziyi bütün olarak temsil edebilecek nitelikte 4 doğrusal hat tespit edilmiştir. Her bir hat içerisinde de şansa bağlı olarak 15 örnekleme ve sonuçta ise her bir çayır kesiminde 60 olmak üzere dört çayır kesiminde toplam 240 örnekleme yapılmıştır. Bu amaçla $0.5 \times 0.5=0.25 \mathrm{~m}^{2}$ lik çerçeveler kullanılmıştır. Teşhis amacıyla bitki örnekleri öğleden önce ve öğleden sonra toplanmış ve örnek alımları bitkilerin farklı gelişme dönemlerinde (çiçeklenme ve generatif) toprak altı kısımları (kök, yumru, rizom) ile birlikte yapılmıştır. Daha sonra arazide toplanan örnekler naylon torbalara konularak laboratuvara taşınmış ve herbaryum çalışmalarına başlanmıştır. Yine tür teşhislerin yapılmasında yardımcı olması düşüncesiyle, arazide her bir bitki türü için farklı gelişme dönemlerinde mümkün olduğu kadar resimler çekilmiştir. Daha sonra bitki teşhisleri alanında uzaman kişilere gönderilmiş ve teşhisleri yaptırılmıştır.

\section{Bulgular ve Tartışma}

İki yıl boyunca dört farklı taban çayır kesimlerinde yapılan floristik kompozisyon çalışması sonucu tespit edilen tür bilişimleri Çizelge 2'de sunulmuştur. Buna göre tuz içermeyen çayır kesiminde 9'u buğdaygil, 8'i baklagil ve 22'si diğer familyalardan olmak üzere toplam 39 tür belirlenmiştir. Bu sonuçlara göre tuz içermeyen çayır kesiminde toplam tür içerisinde buğdaygillerin oranı \%23.0, baklagillerin oranı \%21.0 ve diğer familyaların oranı ise $\% 56.0$ olarak belirlenmiştir. Tuzlu çayır kesiminde toplam 41 tür tespit edilmiş ve bunların 9'u (\%22.0) buğdaygil, 6'sı (\%14.6) baklagil ve 26 'sı (\%63.4) diğer familyalardan oluşmuştur. Alkali çayır kesiminde ise 9'u (\%23.7) buğdaygil, 7'si (\%18.4) baklagil ve 22'si (\%57.9) diğer familyalardan olmak üzere toplam 38 tür belirlenmiştir. Ve son olarak tuzlu-alkali çayır kesiminde toplam 26 tür tespit edilmiştir. Mevcut belirlenen türlerin 5’i (\%19.2) buğdaygil familyasına ait, 4'ü (\%15.4) baklagil ve 17'si $(\% 65.4)$ ise diğer familyalara ait türler 
Çizelge 1. Araştırma sahası topraklarının bazı fiziksel ve kimyasal özellikleri

Table 1. Some physiological and chemical properties of experiment area

\begin{tabular}{lcccc}
\hline Toprak özellikleri & $\begin{array}{c}\text { Tuz içermeyen } \\
\text { çayır kesimi }\end{array}$ & $\begin{array}{c}\text { Tuzlu çayır } \\
\text { kesimi }\end{array}$ & $\begin{array}{c}\text { Alkali çayır } \\
\text { kesimi }\end{array}$ & $\begin{array}{c}\text { Tuzlu-Alkali çayır } \\
\text { kesimi }\end{array}$ \\
\hline pH & 7.89 & 8.32 & 9.69 & 8.8 \\
EC $(\mathrm{dS} / \mathrm{m})$ & 0.40 & 4.82 & 1.48 & 4.31 \\
Kireç $(\%)$ & 13.17 & 6.97 & 11.82 & 12.59 \\
Tekstür sınıfı & Killi tın & Kumlu killi tın & Killi tın & Killi tın \\
Org. Mad. (\%) & 2.41 & 0.69 & 0.89 & 1.10 \\
Azot (\%) & 0.12 & 0.03 & 0.04 & 0.05 \\
KDK (me/100gr) & 25.5 & 65.2 & 40.6 & 46.5 \\
DNa (\%) & 4.3 & 11.6 & 39.1 & 39.7 \\
Fosfor $(\mathrm{ppm})$ & 0.24 & 1.93 & 1.45 & 0.61 \\
Bor (ppm) & 0.37 & 3.09 & 6.68 & 6.14 \\
\hline
\end{tabular}

oluşturmuştur. Familya grupları oransal olarak incelendiğinde en fazla buğdaygil oranı alkali çayır kesiminde (\%23.7), bunu tuz içermeyen (\%23.0) ve tuzlu çayır (\%22.0) kesimleri takip etmiştir. En düşük buğdaygil oranı ise tuzlu-alkali çayır (\%19.2) kesiminde tespit edilmiştir.

Genel olarak türlerin tuzluluğa dayanımları, tuz konsantrasyonlarının yoğunluğuna ve bitki türlerine göre değişkenlik göstermektedir. Mevcut araştırmamızda da dört çayır kesiminde de en az tür sayısı ve oranlarının baklagil familyasında, en fazla tür sayısı ve oranlarının ise diğer familyalara ait olduğu ortaya konulmuştur (Çizelge 2). Ayrıca toprakların bozulum derecesi artıkça, baklagil familyasına ait türlerin oranlarının azaldığı görülmüştür. Yapılan araştırmalar tuzlu toprak koşulları altında bitkilerin çimlenme ve gelişme kabiliyetlerinin familya, cins ve türler arasında farklılık gösterdiğini, hatta aynı bitkinin farklı varyeteler arasında bile önemli varyasyonların olduğunu rapor etmişlerdir (Li et al. 1997; Hakim ve ark. 2010). Çayır kesimlerinin toprak özellikleri dikkate alındığında, tuzlu-alkali çayır kesiminde gerek familyalara ait ve gerekse toplam tür sayıları diğer çayır kesimlerine göre daha düşük bulunmuştur. $\mathrm{Bu}$, topraktaki aşırı tuz ve $\mathrm{Na}$ iyonlarının fazlalığından dolayı bitkilerin fizyolojik kuraklığa ve iyon toksitesine daha fazla maruz kalmasından kaynaklanmış olabilir. Bilindiği üzere kültürü yapılan ve doğada kendiliğinden yetişen çoğu türler halomorfik toprak koşullarına uyum sağlayamazken, tuza toleranslı bazı geofitler ve özellikle de halofit türler rahatça yetişebilmekte (Yılmaz ve ark. 2011), hatta bazı türler (obligat halofitler) en iyi gelişmelerini tuzlu koşullarda gerçekleştirmektedirler (Ungar 1991). Mevcut bu sebeplerden dolayı tuzlu-alkali çayır kesimlerinde bitki gelişimleri ve tür sayısı düşük olmuş olabilir.
Ayrıca mevcut araştırmamızda tuzlu çayır kesimindeki toplam tür sayısı, diğer çayır kesimlerine göre daha yüksek bulunmuştur (Çizelge 2). Özellikle tuzlu çayır kesiminde tür sayısının tuz içermeyen çayır kesimine göre daha fazla olması, baklagil ve buğdaygil familyalarına ait tür sayısının fazlalığından ziyade diğer familyalara ait tür sayısının fazla olmasında kaynaklandığı görülmüştür. Konu ile ilgili olarak Temel ve ark. (2015), tuzlu topraklarda $\mathrm{m}^{2}$ 'de yer alan yabancı ot çeşitliliği ve yoğunluğunun tuz içermeyen topraklara göre daha fazla olduğunu belirtmişlerdir. Mevcut bu sebeplerden dolayı tuzlu çayır kesimine adapte olmuş diğer familyalara ait halofit tür sayısının fazla olması, buna neden olmuş olabilir.

\section{Sonuç}

Topraktaki tuzluluk ve alkalilik çayır kesimlerinin gerek familya bazında ve gerekse toplam tür sayılarını azaltırken, çorakçıl bitkilerin sayılarında artışlara neden olmuştur. Bir başka deyişle değişen toprak koşulları bitki örtüsünün değişmesine sebep olmuştur. Ayrıca mevcut türler dikkate alındığında çayır kesimlerinin bilinçsizce kullanıldığı ve hayvanlar tarafından daha az tercih edilen özellikle halofit tür sayılarında artışlar olduğu ortaya konmuştur. Mevcut bu sonuçlara göre çayır kesimlerinin ot kalitesini yükseltmek ve hayvanlar tarafından daha fazla tercih edilen tür sayılarının artırıması için ekstrem toprak koşullarında yetişebilen ticari türler veya bölge topraklarına adapte olmuş türlerle bitki bileşiminin zenginleştirilmesi gerekmektedir. Ayrıca ikame edilen türlerin habitat oluşturabilmesi ve devamlılıklarını sürdürebilmesi için drenaj problemlerinin çözülmesi ve uygun çayır idare yöntemlerinin uygulanması gerekmektedir. 
Çizelge 2. Tuz içermeyen, tuzlu, alkali ve tuzlu-alkali çayır kesiminde yer alan türler

Table 2. Plant species on meadow zones with no salinity problem, saline, alkaline and saline alkaline meadow zones

\begin{tabular}{|c|c|c|c|c|c|}
\hline Latince adı & Türkçe adı & T.İ.Ç.K & T.Ç.K & A.Ç.K & T.A.Ç.K \\
\hline \multicolumn{6}{|c|}{ BUĞDAYGILLER } \\
\hline Aegilops columnaris ZHUKOVSKY & Buğdayotu & - & + & + & - \\
\hline Aeluropus littoralis L. & Sahil ayrığı & + & + & + & + \\
\hline Agropyron repens L. & Tarla ayrığı & + & - & + & - \\
\hline Alopecurus myosuroides Hudson & Yabani tilkikuyruğu & + & + & + & + \\
\hline Bromus sterilis L. & Sağır ilcan & + & + & + & - \\
\hline Cynodon dactylon (L.) Pers. & Köpekdişi & + & + & + & + \\
\hline Phragmites australis (Cav.) Trin. Ex & Kargı kamışı & + & + & + & + \\
\hline Pucinellia distans (Jacq.) Parl. & Çorak çimi & + & + & + & + \\
\hline Steria viridis (L.) P.Beauv. & Yeşil kirpi darı & + & + & + & - \\
\hline Hordeum nodum & Pisipisi arpası & + & - & - & - \\
\hline Agropyron cristatum ssp incanum & Kop ayrığı & - & + & - & - \\
\hline Toplam Buğdaygiller & & 9 & 9 & 9 & 5 \\
\hline \multicolumn{6}{|c|}{ BAKLAGILLER } \\
\hline Alhagi pseudalhagi (Bieb.) Desv. & Alhagi & + & + & + & + \\
\hline Glycyrrhiza glabra L. & Meyan & + & + & + & + \\
\hline Lotus corniculatus L. var. corniculatus & Gazal boynuzu & + & + & + & + \\
\hline Melilotus officinalis (L.) Desr. & Sarıtaş yoncası & + & + & + & - \\
\hline Sophora alopecuroides L. & Acıbiyan & + & + & + & + \\
\hline Trifolium fragiferum $\mathrm{L}$. & Çilek üçgülü & + & - & + & - \\
\hline Trigonella coelesyriaca Boiss. & Çemen & + & + & + & - \\
\hline Trifolium repens & Ak üçgül & + & - & - & - \\
\hline Toplam Baklagiller & & 8 & 6 & 7 & 4 \\
\hline \multicolumn{6}{|c|}{ DIĞER FAMIL YALAR } \\
\hline Amaranthus retroflexus L. & Horozibiği & - & + & - & - \\
\hline Anchusa azurea MILLER & Balıkotu & - & + & - & - \\
\hline Anthemis cotula L. & Pis kokulu köpek papatya & - & + & - & + \\
\hline Brasica sp. & Hardal & + & - & - & - \\
\hline Capsella bursa-pastoris (L.) Medik. & Çoban çantası & + & - & + & - \\
\hline Carex muricata ssp. lamprocarpa & Çayır sazı & + & + & + & + \\
\hline Chenopodium album L. & Ak kazayağı & - & + & + & + \\
\hline Cichorium intybus L. & Yabani hindiba & + & + & + & + \\
\hline Cirsium arvense (L.) Scop. & Tarla köygöçüreni & + & + & + & - \\
\hline Convolvulus arvensis $\mathrm{L}$. & Tarla sarmaşığı & + & + & + & + \\
\hline Cuscuta europaea L. & Cinsaçı & + & + & + & + \\
\hline Dianthus sp. & Karanfil & + & + & + & + \\
\hline Galium tricornutum Dandy & Yoğurt otu & + & - & + & - \\
\hline Halanthium roseum (Trautv.) Iljin & Tuz otu & - & + & + & + \\
\hline Halimione verrucifera (M. Bieb.) & & - & + & + & + \\
\hline Halostachys belangeriana (Moq.)Botsc & Deniz börülcesi & - & + & - & + \\
\hline Herniaria glabra L. & Kırık Otu & + & + & - & - \\
\hline Inula oculus-christi L. & Yünlü pirekıran & + & + & + & - \\
\hline Juncus gerardi & Hasır sazı & + & - & - & - \\
\hline Lactuca saligna L. & Eşek marulu & + & + & + & - \\
\hline Lappula occidentalis (S.Wats.) Greene & & + & + & - & - \\
\hline Lepidium perfoliatum L. & Yabani tere & + & + & + & - \\
\hline Limonium virgatum (Willd.) Fourr. & Kuyruklu deniz lavantası & - & + & + & + \\
\hline Petrosimonia brachiata (Pall.) Bunge & Soda otu & - & + & + & + \\
\hline Plantago lanceolata L. & Mızrak yapraklı sinir otu & + & + & + & + \\
\hline Plantago media L. & Orta yapraklı sinir otu & + & + & + & - \\
\hline Polygonum aviculare agg. & Kuşekmeği & + & + & + & + \\
\hline Potentilla reptans $\mathrm{L}$. & Sürünücü beşparmak otu & + & - & - & - \\
\hline Scorzonera cana (C.A.Mey.) Hoffm & İskorçin & + & + & + & + \\
\hline Taraxacum officinale $\mathrm{L}$. & Aslan dişi & + & + & + & + \\
\hline Tragopogon dubius Scop. & Yemlik & + & + & + & - \\
\hline Toplam Diğer Familyalar & & 22 & 26 & 22 & 17 \\
\hline Genel Toplam Tür Sayısı & & 39 & 41 & 38 & 26 \\
\hline Buğdaygillerin oranı (\%) & & 23.0 & 22.0 & 23.7 & 19.2 \\
\hline Baklagillerin oranı (\%) & & 21.0 & 14.6 & 18.4 & 15.4 \\
\hline Diğer familyaların oranı (\%) & & 56.0 & 63.4 & 57.9 & 65.4 \\
\hline
\end{tabular}

+: Var olan türler, -: Var olmayan türler, T.I.Ç.K.: Tuz içermeyen çayır kesimi, T.Ç.K.: Tuzlu çayır kesimi, A.Ç.K.: Alkali çayır kesimi, T.A.Ç.K.: Tuzlu-alkali çayır kesimi

+: Existing species, -:Non existing species, T. I. C. K.: Meadow zones with no salinity problem, T. C.. K.: Saline meadow zone, A. Ç. K: : Alkaline meadow zone, T. A. Ç. K. : Saline - alkaline meadow zone. 


\section{Teşekkür}

Bu araştırma (2012-FBE-B10 No.lu) Iğdır Üniversitesi Bilimsel Araştırma Projeleri Koordinasyon Birimi tarafından desteklenmiştir. Tüm yazarlar finansman desteğinden dolayı BAP Birimine teşekkür etmektedir.

\section{Kaynaklar}

Açıkgöz E., 2001. Yembitkileri (3. baskı). Uludağ Üniversitesi Güçlendirme Vakfı, Yayın No: 182, VIPAŞ A.Ş. Yayın No: 58, 584s. Bursa

Anonim, 2014. Başbakanlık DMi Genel Müdürlüğü Meteoroloji Bültenleri, Ankara.

Anonim, 1980. Soil testing and plant analysis, Bull. 38/1 Food and Agriculture Organization, Rome-Italy

Anonim, 2002a. Explanation of Physical Analysis and Interpretaion. http:Ilwww.dlwc.nsw. gov.aul carelsoillssultestsitests4.htm (Erişim tarihi 22.06.2015)

Anonim, 2002b Explanation of Chemical Analysis and Interpretaion. http:Ilwww. dlwc.nsw.gov. aulcarelsoillssultestsitests5.htm\#ChemicalTest-Result-Rankings (Erişim tarihi 22.06.2015)

Aydın İ. ve Uzun F., 2002. Çayır-Mera Amenajmanı ve Islahı. Ondokuz Mayıs Üniversitesi Ziraat Fakültesi Ders Kitabı No: 9, Samsun, 313 s

Çetik A.R., 1985. Türkiye Vejetasyonu: I İç Anadolu'nun Vejetasyonu ve Ekolojisi, Selçuk Üniv. Yay. No:7, Konya

Gomez Mercado F., Del Moral Torres F., Gimenez Luque E. and De Haro Lozano S., 2012. Salinity tolerance of the hygrophilous plant species in the wetlands of the south of the Iberian Peninsula. Not Bot Horti Agrobo, 40(1): $18-28$

Hakim M.A., Juraimi A.S., Begum M., Hanafi M.M., Ismail M.R. and Selamat A., 2010. Effect of salt stress on germination and early seedling growth of rice. Afr. J. Biotech., 9(13): 19111918

Holechek Jery L., Pieper R.D. and Herbel C.H., 1995. Range Management: Principles and Practices. Prentice Hall, Englewood Cliffs, New Jersey 07632, p 526
Joachim H., Makoi J.R. and Ndakidemi P.A., 2007 Reclamation of sodic soils in northern tanzania, using locally available organic and inorganic resources. African J. Biotechnology, 6(16): 1926-31

Koç A. ve Gökkuş A., 1996. Palandöken dağları mera vejetasyonunda yer alan bitkilerin bazı özellikleri. Türkiye 3. Çayır mera ve Yem Bitkileri Kongresi 17-19 Haziran 1996, Erzurum, s. 107-114

Kushiev H., Noble A.D., Abdullaev I. and Toshbekov U., 2005. Remediation of abandoned saline soils using Glycyrrhiza glabra: A study from the Hungry steppes of Central Asia. International Journal of Agricultural Sustainability, 3(2): 102-13

Li Y., Shen Y.Y. and Yan S.G., 1997. Comparative studies of effect of $\mathrm{NaCl}$ stress on the seed germination of 5 forage species. Horticultural Science, 14(2): 50-53

Lund H.G., 2007. Accounting for the World's Rangelands. Rangelands, 29: 3-10

Temel S. ve Şahin K., 2011. Iğdır ilinde yem bitkilerinin mevcut durumu, sorunları ve çözüm önerileri. YYÜ Tar. Bil. Derg., 21(1) 64-72

Temel S., Keskin B., Şimşek U. ve Yılmaz İ.H., 2015. Bazı çok yıllık yem bitkisi türlerinin m2'deki bitki çıkışına halomorfik toprak koşullarının etkisi. Tekirdağ Ziraat Fakültesi Dergisi, 12(1): 46-54

TÜIK 2013. Türkiye İstatistik Kurumu, www.tuik.gov.tr

Tükel T. ve Hatipoğlu R., 2001. Çayır meralarda zehirli bitkiler ve hayvanlar üzerindeki etkileri. Tarım ve Köy İşleri Dergisi, Mayıs-Haziran, Sayı: 139, 40-43

Ungar I.A., 1991. Ecophysiology of Vascular Plants. Boca Raton, Florida: CRC Press, ss. 108.

Yılmaz E., Tuna A.L. ve Bürün B., 2011. Bitkilerin tuz stresi etkilerine karşı geliştirdikleri tolerans stratejileri. C.B.Ü. Fen Bilimleri Dergisi, 7(1): 47-66 